Atmos. Chem. Phys., 18, 10759-10772, 2018

https://doi.org/10.5194/acp-18-10759-2018

(C) Author(s) 2018. This work is distributed under

the Creative Commons Attribution 4.0 License.

\title{
Simulation of atmospheric organic aerosol using its volatility-oxygen-content distribution during the PEGASOS 2012 campaign
}

\author{
Eleni Karnezi ${ }^{1}$, Benjamin N. Murphy ${ }^{2}$, Laurent Poulain ${ }^{3}$, Hartmut Herrmann ${ }^{3}$, Alfred Wiedensohler ${ }^{3}$, \\ Florian Rubach $^{3,4,5}$, Astrid Kiendler-Scharr ${ }^{4}$, Thomas F. Mentel ${ }^{4}$, and Spyros N. Pandis ${ }^{1,6,7}$ \\ ${ }^{1}$ Department of Chemical Engineering, Carnegie Mellon University, Pittsburgh, USA \\ ${ }^{2}$ National Exposure Research Laboratory, United States Environmental Protection Agency, \\ Research Triangle Park, North Carolina, USA \\ ${ }^{3}$ Leibniz Institute for Tropospheric Research, Permoserstr 15, 04318 Leipzig, Germany \\ ${ }^{4}$ Institut für Chemie und Dynamik der Geosphäre, ICG, Forschungszentrum Jülich, Jülich, Germany \\ ${ }^{5}$ Max Planck Institute for Chemistry, 55128 Mainz, Germany \\ ${ }^{6}$ Department of Chemical Engineering, University of Patras, Patra, Greece \\ ${ }^{7}$ Institute of Chemical Engineering Sciences, FORTH/ICEHT, Patra, Greece
}

Correspondence: Spyros Pandis (spyros@ chemeng.upatras.gr)

Received: 6 January 2018 - Discussion started: 22 January 2018

Revised: 12 June 2018 - Accepted: 2 July 2018 - Published: 27 July 2018

\begin{abstract}
A lot of effort has been made to understand and constrain the atmospheric aging of the organic aerosol (OA). Different parameterizations of the organic aerosol formation and evolution in the two-dimensional volatility basis set (2D-VBS) framework are evaluated using ground and airborne measurements collected in the 2012 Pan-European Gas AeroSOls-climate interaction Study (PEGASOS) field campaign in the Po Valley (Italy). A number of chemical aging schemes are examined, taking into account various functionalization and fragmentation pathways for biogenic and anthropogenic OA components. Model predictions and measurements, both at the ground and aloft, indicate a relatively oxidized OA with little average diurnal variation. Total $\mathrm{OA}$ concentration and $\mathrm{O}: \mathrm{C}$ ratios are reproduced within experimental error by a number of chemical aging schemes. Anthropogenic secondary OA (SOA) is predicted to contribute $15-25 \%$ of the total OA, while SOA from intermediate volatility compound oxidation contributes another 20 $35 \%$. Biogenic SOA (bSOA) contributions varied from 15 to $45 \%$ depending on the modeling scheme. Primary OA contributed around $5 \%$ for all schemes and was comparable to the hydrocarbon-like OA (HOA) concentrations derived from the positive matrix factorization of the aerosol mass spectrometer (PMF-AMS) ground measurements. The
\end{abstract}

average $\mathrm{OA}$ and $\mathrm{O}: \mathrm{C}$ diurnal variation and their vertical profiles showed a surprisingly modest sensitivity to the assumed vaporization enthalpy for all aging schemes. This can be explained by the interplay between the partitioning of the semivolatile compounds and their gas-phase chemical aging reactions.

\section{Introduction}

Atmospheric aerosol plays an important role in the Earth's energy balance by absorbing and scattering solar radiation (direct effect) and influencing the properties and lifetime of clouds (indirect effects) (IPCC, 2013). At the same time, certain particles may have significant negative effects on human health, including premature death, increases in respiratory illnesses, and cardiopulmonary mortality (Pope III et al., 2009; Caiazzo et al., 2013).

Aerosol particles contain a wide variety of inorganic and organic compounds, with organics representing about $50 \%$ of the fine $(<1 \mu \mathrm{m})$ aerosol particle mass concentration, on average (Zhang et al., 2007). OA originates from many different natural and anthropogenic sources and processes. It can be emitted directly from fossil fuel and biomass com- 
bustion (so-called primary organic aerosol, POA) or can be formed by the atmospheric oxidation of organic vapors (secondary organic aerosol, SOA). The oxidation pathways of organic compounds are complex and the corresponding reactions lead to hundreds or even thousands of mostly unknown oxygenated products. As a result, our understanding of OA formation mechanisms and its chemical and physical properties remains incomplete.

The use of lumped species is a computationally efficient approach for the representation of OA in atmospheric chemical transport models (CTMs; Pandis et al., 1992). The volatility basis set framework (VBS, Donahue et al., 2006) lumps these compounds into surrogates along an axis of volatility. This approach typically employs species with effective saturation concentrations at $298 \mathrm{~K}$ separated by 1 order of magnitude, with values ranging from, say, 0.01 to $10^{6} \mu \mathrm{g} \mathrm{m}^{-3}$. By quantifying the volatility distributions of primary and secondary OA, a physically reasonable, yet suitable for largescale chemical transport models, description of semi-volatile organics can be obtained (Lane et al., 2008).

The VBS framework was extended by Donahue et al. (2011, 2012a) adding another dimension, the oxygen content (expressed as the ratio of oxygen to carbon atoms, $\mathrm{O}: \mathrm{C}$ ), for the description of the OA chemical aging reactions. In the first application of this framework in a CTM, Murphy et al. (2011) used 12 logarithmically spaced volatility bins (effective saturation concentration $C^{*}$ varying from $10^{-5}$ to $10^{6} \mu \mathrm{g} \mathrm{m}^{-3}$ at $298 \mathrm{~K}$ ) and 13 bins of $\mathrm{O}: \mathrm{C}$ (from 0 to 1.2 with a step of 0.1 ). In this way, 156 surrogate species were included in the model for each OA type. Five organic aerosol types were simulated separately: anthropogenic secondary organic aerosol (aSOA-v) produced during the oxidation of anthropogenic volatile organic compounds (VOCs; aromatics, alkenes, and alkanes); biogenic secondary organic aerosol (bSOA) formed by the oxidation of biogenic VOCs (isoprene, monoterpenes, and sesquiterpenes); fresh primary organic aerosol (POA) which may evaporate and recondense during its atmospheric lifetime, but once it reacts with $\mathrm{OH}$ it becomes secondary OA; secondary organic aerosol (SOA-sv) from the oxidation of semi-volatile organic compounds, that is primary OA that has evaporated and reacted and SOA from the oxidation of intermediate volatility compounds (SOAiv) with saturation concentrations larger than $1000 \mu \mathrm{g} \mathrm{m}^{-3}$. Details about this terminology can be found in Murphy et al. (2014).

Murphy et al. (2011, 2012) used a one-dimensional Lagrangian CTM (PMCAMx-Trj) as the host model for the simulations. PMCAMx-Trj simulates the chemical evolution of a column of air as it travels towards a user-selected receptor site. Three alternative parameterizations of the OA formation and chemical aging were evaluated using measurements of $\mathrm{O}: \mathrm{C}$ and $\mathrm{OA}$ in three European sites (Murphy et al., 2011, 2012). The simplest approach parameterizing the chemical aging of anthropogenic compounds, assuming a net reduction of volatility by one bin during every aging reac- tion step accompanied by an increase of one or two oxygen atoms with an equal probability, was the most successful. A more complex formulation of the chemical aging assumed that functionalization was the only process taking place and overpredicted the OA concentration while it underpredicted $\mathrm{O}: \mathrm{C}$ in most cases. Adding fragmentation reactions together with the functionalization gave promising results, but it was clear that the various parameters of the scheme were not well constrained, leading to large uncertainties in the simulation results, especially during summertime. Murphy et al. (2012) concluded that the 2D-VBS scheme that was used needs additional testing before it is ready for application in threedimensional CTMs.

There is significant second- and later-generation production of SOA from anthropogenic precursors (Hildebrandt Ruiz et al., 2015) while the corresponding later production of SOA from biogenic precursors may be smaller (Ng et al., 2006; Tritscher et al., 2011; Szidat et al., 2006; Gilardoni et al., 2011; Yttri et al., 2011; Zhao et al., 2015). In Murphy and Pandis $(2009,2010)$ and Murphy et al. (2012), formation of significant bSOA during second- and latergeneration aging reactions led to overestimation of OA concentration at both urban and rural sites. However, the firstgeneration products of the oxidation of biogenic VOCs do continue to react in the atmosphere. The net effect on ambient bSOA levels of these chemical aging reactions remains uncertain.

Fragmentation of organic compounds during chemical aging is an important reaction pathway (Chacon-Madrid and Donahue, 2011; Murphy et al., 2011; Hermansson et al., 2014). During fragmentation reactions carbon bonds break, resulting in smaller compounds, which are more volatile than their precursors. A fragmentation probability, depending on $\mathrm{O}: \mathrm{C}$, has been used in the 2D-VBS framework (Donahue et al., 2011, 2012b). A fragmentation probability, ranging from $0-0.4$, has been used in the statistical oxidation model $(\mathrm{SOM})$ that uses the carbon $(\mathrm{C})$ and oxygen $(\mathrm{O})$ atoms per compound as the independent variables (Cappa and Wilson, 2012). While the fragmentation pathways are clearly important for the OA levels, their parameterizations in existing models remain quite uncertain (Murphy et al., 2012).

The effect of temperature on the partitioning of OA components between the gas and particulate phases represents another source of uncertainty. Sheehan and Bowman (2001), focusing on the first generation of SOA production, concluded that a $10^{\circ} \mathrm{C}$ decrease in temperature can result in an increase in SOA by as much as $150 \%$ depending on the assumed vaporization enthalpy. This effect can theoretically lead to significant OA vertical gradients. Simulating both the first and later generations of reactions in the system while applying the 2D-VBS to FAME-08 in Finokalia, Greece, Murphy et al. (2011) reported low sensitivity of the OA concentration and $\mathrm{O}: \mathrm{C}$ ratio measurements to the assumed vaporization enthalpy, with higher values leading to slightly lower $\mathrm{O}: \mathrm{C}$. 
In this study, we evaluate different chemical aging mechanisms in the 2D-VBS approach focusing on the Po Valley in Italy. Extensive measurements were performed both at the ground and aloft from 6 June until 8 July 2012. The Po Valley has major air quality problems due to both industrial and agricultural sources. A number of alternative chemical aging mechanisms are evaluated by comparing the resulting 2D-VBS predictions against the PEGASOS (PanEuropean Gas AeroSOls-climate interaction Study) measurements. The role of bSOA chemical aging is explored. Finally, the sensitivity of the model to the assumed effective vaporization enthalpy is quantified in an effort to constrain this uncertain variable using the measurements aloft.

\section{Lagrangian CTM description}

A one-dimensional Lagrangian chemical transport model (PMCAMx-Trj) (Murphy et al., 2011, 2012) simulating the air parcels that arrive at the desired receptor location is used as the host for the 2D-VBS module. The model solves the general dynamic equation taking into account the following relevant atmospheric processes: atmospheric transport, gas- and aqueous-phase chemistry, dry and wet deposition of gases and aerosols, vertical turbulent dispersion, and area and point emissions. Ten computational cells are used to cover heights up to $3 \mathrm{~km}$. The lowest cell has a height of $60 \mathrm{~m}$. The SAPRC chemical mechanism is used for the simulation of gas-phase chemistry. The meteorological parameters (horizontal winds, temperature, pressure, vertical dispersion coefficients, water vapor, clouds, rainfall, and land use) used as inputs in the model are provided by the Weather Research and Forecasting Model (WRF). The WRF simulation was periodically re-initialized (every 3 days) to ensure the accuracy of the inputs to the CTM. Area and point emissions, both anthropogenic and biogenic, were also provided as hourly inputs for the European domain. The Global and regional Earth-system Monitoring using Satellite and in situ data (GEMS) dataset (Visschedijk et al., 2007) is used for the emissions of anthropogenic gases. Anthropogenic emissions of organic and elemental carbon are based on the PanEuropean Carbonaceous Aerosol Inventory developed during EUCAARI (European Integrated project on Aerosol Cloud Climate and Air Quality Interactions; Kulmala et al., 2009). Biogenic gridded emissions are produced from the combination of three different models. The Model of Emissions of Gases and Aerosols from Nature (MEGAN) provides the emissions from terrestrial ecosystems (Guenther et al., 2006), the O'Dowd et al. (2008) model provides the marine aerosol emissions, and wildfire emissions are included following Sofiev et al. (2008a, b). Details of the emission inventory used for Europe can be found in Fountoukis et al. (2011). In order to implement these emissions in our 2D-VBS model, we used the same volatility distribution of the emissions as in the original work (Fountoukis et al., 2011) and used the
Murphy et al. (2012) methodology for mapping these to the 2D-VBS. Vertically resolved initial conditions and the top boundary conditions for PMCAMx-Trj were obtained from the corresponding output of the PMCAMx regional-scale three-dimensional simulation for the same period.

\subsection{Simulated periods}

The Hybrid Single Particle Lagrangian Integrated Trajectory (HYSPLIT) model (Draxler et al., 2009) was used to calculate $72 \mathrm{~h}$ back trajectories arriving at the ground site of San Pietro Capofiume. Six air parcels arriving at 03:00, 07:00, 11:00, 15:00, 19:00, and 23:00 local time (UTC+1) in the ground site of San Pietro Capofiume were simulated for a total of 7 days $(15,26,27$, and 28 June and 4, 5, and 8 July 2012). The air masses in the simulated trajectories originated all from Europe (mostly Portugal or France) or the Atlantic Ocean. We avoided days during which air masses originated from Africa since emission inventories for Africa are quite uncertain. We chose days for which the trajectories at the different altitudes originated all from the same region. Following Murphy et al. (2011) we used the ensemble average of 20 trajectories with varied heights from $60 \mathrm{~m}$ up to $3 \mathrm{~km}$. For consistency, we used the same WRF meteorological data as input to HYSPLIT to calculate the back trajectories.

The $2072 \mathrm{~h}$ HYSPLIT back trajectories arriving at San Pietro Capofiume at 03:00 LT on 8 July 2012 are shown in Fig. 1 as an example. They all originated from the eastern Atlantic Ocean, passed a day over the ocean, and then traveled over Portugal and Spain for another day. The air masses continued over the Mediterranean Sea, western Italy, and a few hours later arrived in the receptor site of San Pietro Capofiume. The HYSPLIT clustering analysis utility was used to estimate the average trajectory that was used in the simulations (Fig. 1).

Zeppelin flights over the Po Valley took place on 20, 21, 22, and 24 June 2012 and 1, 3, and 4 July 2012. The HYSPLIT model was once again used to calculate the $72 \mathrm{~h}$ back trajectories. The Zeppelin trajectories were based on the actual Zeppelin position every hour, so that we could use all the measurements from all the flights. All the flights took place between 04:00 and 13:00 LT. The flight path of the Zeppelin for 4 June 2012 is shown in Fig. S1 in the Supplement as an example. The flight took place between 05:00 and 10:00 LT and the measurements took place in the nighttime boundary layer, the residual layer, and also in the mixed layer later in the day. For each trajectory and for each hour the corresponding emissions are selected from the gridded emissions inventory files. At the same time, the meteorological parameters (temperature, humidity, rain, etc.) are selected from the WRF meteorological data files for each point and hour of the trajectory. 

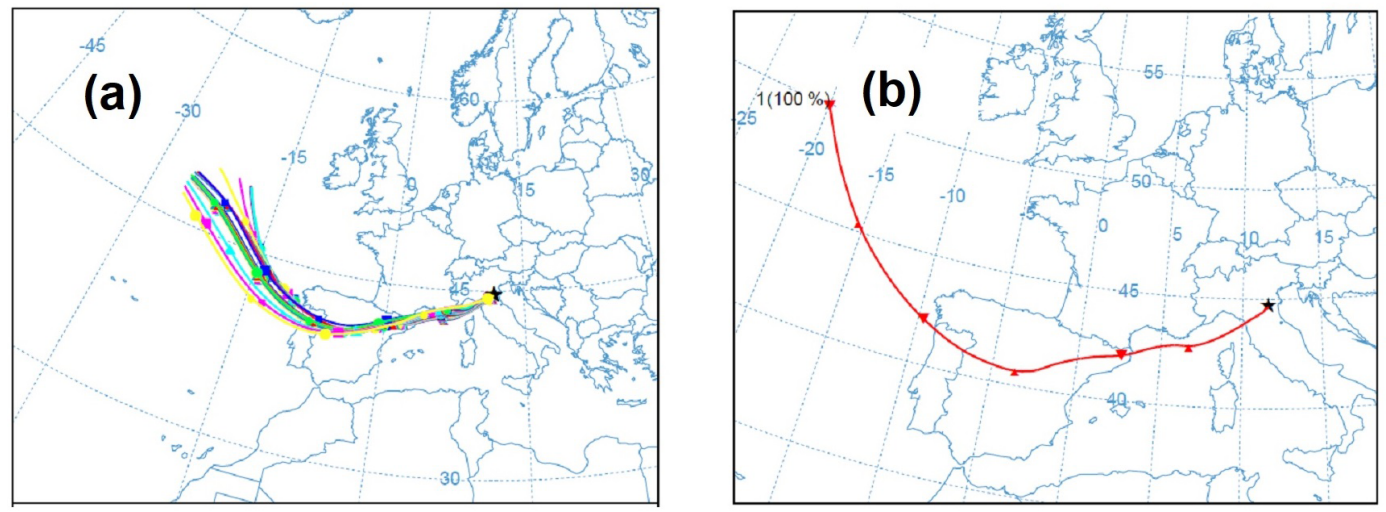

Figure 1. (a) The ensemble of $2072 \mathrm{~h}$ back trajectories calculated by HYSPLIT for air parcels arriving at the San Pietro Capofiume site on 8 July 2012 at 03:00 LT and (b) the ensemble average trajectory calculated by the HYSPLIT clustering utility.

\subsection{Chemical aging schemes}

In our simulations, we considered three different functionalization schemes, two bSOA chemical aging parameterizations, and explored the use of fragmentation mechanisms. These are summarized below.

\subsubsection{Functionalization schemes}

\section{Simple scheme}

The first functionalization scheme (one-bin) used in our simulations was the simple scheme of Murphy et al. (2012) that had the best performance in the cases simulated in that study. In this scheme, there is one volatility bin reduction for every reaction with a simultaneous increase in oxygen atoms, with a probability of $50 \%$ for an increase of one oxygen atom and $50 \%$ probability for an increase of two oxygen atoms. The calculation of the $\mathrm{O}: \mathrm{C}$ change from the number of added oxygen atoms is based on Donahue et al. (2011). The chemical aging reaction constants that are used for the reactions with $\mathrm{OH}$ are the same as in the base case of Murphy et al. (2011) with values equal to $1 \times 10^{-11} \mathrm{~cm}^{3} \mathrm{molec}^{-1} \mathrm{~s}^{-1}$ for anthropogenic SOA from VOCs (aSOA-v) and biogenic SOA (bSOA) and $4 \times 10^{-11} \mathrm{~cm}^{3} \mathrm{molec}^{-1} \mathrm{~s}^{-1}$ for SOA from semi-volatile OA (SOA-sv) and intermediate volatility compounds (SOA-iv). These values are based on the average size of the corresponding compounds, with higher values for the bigger organic molecules.

The simple functionalization scheme has the advantage that it can also be implemented in the 1D-VBS, with much lower computational cost. In this case, the predictions of OA mass concentration and the volatility distributions remain the same, but one loses the ability to predict the $\mathrm{O}: \mathrm{C}$.

\section{Two-bin shift simple scheme}

In the second functionalization scheme (two-bin), a two-bin volatility reduction is assumed for every reaction with a si- multaneous increase in oxygen atoms. A $50 \%$ probability for the increase of one oxygen atom and $50 \%$ probability for the increase of two oxygen atoms are used. The calculation of the $\mathrm{O}: \mathrm{C}$ shift in bins from the number of added oxygen atoms is based again on Donahue et al. (2011). This functionalization scheme assumes a more rapid reduction in volatility for every reaction and uses the same reaction constants for the reactions with $\mathrm{OH}$ as in the base case of Murphy et al. (2011).

This simple functionalization scheme has again the advantage that it can also be implemented in the 1D-VBS, with much lower computational cost but without the ability to predict the $\mathrm{O}: \mathrm{C}$.

\section{Detailed scheme}

The third aging scheme is the detailed functionalization scheme (DET) introduced by Donahue et al. (2011). This is a more rigorous scheme compared to the previous two conservative aging parameterizations. Following Murphy et al. (2012), there is a $30 \%$ probability of adding one $\mathrm{O}$ atom, $50 \%$ probability of adding two $\mathrm{O}$ atoms, and $20 \%$ probability of adding three $\mathrm{O}$ atoms. Each addition of $\mathrm{O}$ atoms results in a different distribution of volatility reductions, with an average reduction of -1.75 in $\log _{10} C^{*}$ per oxygen group added. These additions of $\mathrm{O}$ atoms are translated to changes of $\mathrm{O}: \mathrm{C}$ ratios following Murphy et al. (2012). The functionalization kernel is applied to all species in the 2D-VBS upon $\mathrm{OH}$ reaction. Again the chemical aging reaction constants that are used for the reaction with $\mathrm{OH}$ are the same as the two functionalization schemes described above. Murphy et al. (2011) investigated the sensitivity of the results of the model to the various assumed reaction constants and concluded that their effect on the results was low to moderate.

\subsection{2 bSOA aging parameterizations}

Since the net effect of chemical aging reactions with $\mathrm{OH}$ radicals on ambient bSOA levels remains uncertain, two differ- 
Table 1. Characteristics of the different parameterizations used in our simulations.

\begin{tabular}{lllll}
\hline $\begin{array}{l}\text { Parameterization } \\
\text { name }\end{array}$ & $\begin{array}{l}\text { Functionalization } \\
\text { scheme }\end{array}$ & $\begin{array}{l}\text { bSOA increase } \\
\text { during aging }\end{array}$ & $\begin{array}{l}\text { Fragmentation } \\
\text { probability }\end{array}$ & Comments \\
\hline $\begin{array}{l}\text { One-bin } \\
\text { One-bin/bSOA }\end{array}$ & $\begin{array}{l}\text { One-bin } \\
\text { One-bin }\end{array}$ & No & $b=0$ & \\
One-bin & One-bin & No & $b=0$ & \\
One-bin/bSOA $/ b=0.15$ & One-bin & Yes & $b=0-1$ & Optimum for $b=0$, same as one-bin case \\
Two-bin & Two-bin & No & $b=0$ & Optimum for $b=0.15$ \\
Two-bin/bSOA & Two-bin & Yes & $b=0$ & \\
Two-bin $/ b=0.1$ & Two-bin & No & $b=0-1$ & Optimum for $b=0.1$ \\
Two-bin/bSOA $/ b=0.4$ & Two-bin & Yes & $b=0-1$ & Optimum for $b=0.4$ \\
DET & DET & No & $b=0$ & \\
DET/bSOA & DET & Yes & $b=0$ & \\
DET $/ b=0.3$ & DET & No & $b=0-1$ & Optimum for $b=0.3$ \\
DET/bSOA $/ b=0.7$ & DET & Yes & $b=0-1$ & Optimum for $b=0.7$ \\
\hline
\end{tabular}

ent parameterizations of bSOA aging are explored. While the fundamentals of the aging scheme are the same for all compounds and it is assumed that homogeneous reactions with $\mathrm{OH}$ radicals are the main chemical pathway, the effect of these reactions on the volatility distribution of the secondary organic compounds is allowed to differ between biogenic and anthropogenic SOA components. In the first scheme, the chemical aging of biogenic SOA is assumed to result in a negligible net change in volatility but an increase in $\mathrm{O}: \mathrm{C}$ (Murphy et al., 2011). This scheme is consistent with the lack of bSOA aging that has been used in PMCAMx (Murphy and Pandis, 2009, 2010) and is called in the rest of the paper nobSOA aging even if the $\mathrm{O}: \mathrm{C}$ of bSOA does change.

In the second scheme, bSOA components are assumed to age similarly to aSOA, with their processing leading not only to changes in $\mathrm{O}: \mathrm{C}$, but also to a net reduction of their volatility. We explore all three functionalization schemes, the simple scheme (one-bin), the faster functionalization (two-bin), and the detailed functionalization scheme together with the two bSOA aging parameterizations.

\subsubsection{Fragmentation parameterizations}

Fragmentation parameterizations will be examined that lead to products with lower carbon numbers than the precursor. As in Murphy et al. (2012) the bond cleavage is assumed to happen randomly and to be uniformly distributed throughout the carbon backbone. For these fragmented compounds, the functionalization kernel is applied and this will lead to increases in volatility. In all tests described in this work a constant fragmentation probability was assumed during the full corresponding simulation. This value was allowed to range from zero (for no fragmentation) to unity. In principle, this probability should depend on $\mathrm{O}: \mathrm{C}$. However, we have assumed a constant value in order to avoid introducing more free parameters in our schemes.

\subsection{Combination of parameterizations}

In our simulations, we used all combinations of the three functionalization schemes (one-bin, two-bin, or DET), the two bSOA aging schemes, and simulated fragmentation assuming fragmentation probability $b$ ranging from zero to 1 . In Table 1, we summarize the parameterizations that were finally chosen for the simulations. For each of the six combinations of functionalization and bSOA aging, we assumed zero fragmentation probability (six cases) plus we determined the fragmentation probability $b$ that resulted in the minimum error for the average OA concentration. The determination of the optimum fragmentation probability for each case is shown in Fig. S5 in the Supplement. For the one-bin functionalization scheme and considering no bSOA production during aging, the OA was underpredicted for fragmentation probabilities even as low as $5 \%$, so in this case the optimum $b$ was equal to zero and this became the same as the one-bin simple scheme of Murphy et al. (2012).

\subsection{Evaluation of parameterizations}

The prediction skill of our simulations is quantified in terms of the fractional error, the fractional bias, the absolute error, the absolute bias, and the root mean square error. The definitions of these metrics can be found in the Supplement. We use the hourly predictions from the simulation of each parameterization and the hourly measurements at the receptor site of San Pietro Capofiume, or the Zeppelin measurements above the Po Valley for the model evaluation.

\section{Results}

\subsection{Simple functionalization (one-bin case)}

The first set of simulations used the simple functionalization scheme (one-bin), assuming negligible production of bSOA 
Table 2. Performance metrics of different parameterizations during the PEGASOS campaign for ground $\mathrm{O}: \mathrm{C}$ measurements. The measured average $\mathrm{O}: \mathrm{C}$ was 0.58 .

\begin{tabular}{lrrrrrr}
\hline $\begin{array}{l}\text { 2D-VBS } \\
\text { parameterization }\end{array}$ & $\begin{array}{r}\text { Predicted } \\
\text { average }\end{array}$ & $\begin{array}{r}\text { Fractional } \\
\text { error }\end{array}$ & $\begin{array}{r}\text { Fractional } \\
\text { bias }\end{array}$ & $\begin{array}{r}\text { Absolute } \\
\text { error }\end{array}$ & $\begin{array}{r}\text { Absolute } \\
\text { bias }\end{array}$ & $\begin{array}{r}\text { Root mean } \\
\text { square error }\end{array}$ \\
\hline one-bin & 0.64 & 0.1 & 0.09 & 0.06 & 0.06 & 0.08 \\
one-bin/bSOA & 0.55 & 0.07 & -0.06 & 0.04 & -0.03 & 0.05 \\
one-bin/bSOA $/ b=0.15$ & 0.56 & 0.07 & -0.04 & 0.04 & -0.02 & 0.05 \\
two-bin & 0.63 & 0.09 & 0.08 & 0.05 & 0.05 & 0.06 \\
two-bin/bSOA & 0.53 & 0.10 & -0.10 & 0.05 & -0.05 & 0.06 \\
two-bin/b=0.1 & 0.65 & 0.12 & 0.11 & 0.07 & 0.07 & 0.08 \\
two-bin/bSOA $/ b=0.4$ & 0.58 & 0.05 & 0.0 & 0.03 & 0.00 & 0.04 \\
DET & 0.41 & 0.34 & -0.34 & 0.17 & -0.17 & 0.17 \\
DET/bSOA & 0.35 & 0.49 & -0.49 & 0.23 & -0.23 & 0.23 \\
DET/b=0.3 & 0.57 & 0.05 & -0.03 & 0.03 & -0.01 & 0.04 \\
DET/bSOA $/ b=0.7$ & 0.62 & 0.08 & 0.06 & 0.05 & 0.04 & 0.05 \\
\hline
\end{tabular}

Table 3. Performance metrics of different parameterizations during the PEGASOS campaign for ground OA mass measurements. The measured average organic aerosol concentration was $2.8 \mu \mathrm{g} \mathrm{m}^{-3}$.

\begin{tabular}{|c|c|c|c|c|c|c|}
\hline $\begin{array}{l}\text { 2D-VBS } \\
\text { parameterization }\end{array}$ & $\begin{array}{l}\text { Predicted average } \\
\qquad\left(\mu \mathrm{g} \mathrm{m}^{-3}\right)\end{array}$ & $\begin{array}{r}\text { Fractional } \\
\text { error }\end{array}$ & $\begin{array}{r}\text { Fractional } \\
\text { bias }\end{array}$ & $\begin{array}{r}\text { Absolute error } \\
\left(\mu \mathrm{g} \mathrm{m}^{-3}\right)\end{array}$ & $\begin{array}{r}\text { Bias } \\
\left(\mu \mathrm{g} \mathrm{m}^{-3}\right)\end{array}$ & $\begin{array}{l}\text { Root mean square } \\
\quad \text { error }\left(\mu \mathrm{g} \mathrm{m}^{-3}\right)\end{array}$ \\
\hline one-bin & 2.6 & 0.29 & -0.12 & 0.78 & -0.25 & 0.89 \\
\hline one-bin/bSOA & 3.8 & 0.3 & 0.26 & 1.09 & 0.97 & 1.50 \\
\hline one-bin $/ \mathrm{bSOA} / b=0.15$ & 2.9 & 0.27 & -0.02 & 0.79 & 0.05 & 0.96 \\
\hline two-bin & 3.4 & 0.23 & 0.16 & 0.76 & 0.56 & 1.06 \\
\hline two-bin/bSOA & 5 & 0.54 & 0.54 & 2.21 & 2.21 & 2.53 \\
\hline two-bin $/ b=0.1$ & 2.9 & 0.22 & 0.02 & 0.67 & 0.11 & 0.85 \\
\hline two-bin $/ \mathrm{bSOA} / b=0.4$ & 3.1 & 0.22 & 0.07 & 0.71 & 0.3 & 0.96 \\
\hline DET & 3.2 & 0.21 & 0.11 & 0.67 & 0.4 & 0.93 \\
\hline $\mathrm{DET} / \mathrm{bSOA}$ & 5.4 & 0.6 & 0.6 & 2.53 & 2.53 & 2.80 \\
\hline $\mathrm{DET} / b=0.3$ & 2.9 & 0.22 & 0.01 & 0.66 & 0.1 & 0.84 \\
\hline $\mathrm{DET} / \mathrm{bSOA} / b=0.7$ & 2.9 & 0.24 & 0.02 & 0.71 & 0.12 & 0.87 \\
\hline
\end{tabular}

during aging (no bSOA aging), and neglected fragmentation, assuming that the employed functionalization scheme represents the net effect of these pathways. This case is the same as the base case of Murphy et al. (2012). In this scheme, there is a modest volatility reduction as the organic vapors react with $\mathrm{OH}$. The prediction skill metrics of the model $4 \mathrm{~h}$ average $\mathrm{O}: \mathrm{C}$ and $\mathrm{OA}$ concentration against the averaged ground measurements for the seven selected days during the PEGASOS 2012 campaign are summarized in Tables 2 and 3 respectively. Here we have to note that the use of $4 \mathrm{~h}$ long time periods (six periods per day of simulation) was a compromise between keeping the computational cost of the hundreds of simulations performed low and maintaining most of the variability of $\mathrm{OA}$ and $\mathrm{O}: \mathrm{C}$. We tried simulations with hourly resolution for selected schemes and the differences were marginal.

The average predicted diurnal variation of $\mathrm{O}: \mathrm{C}$ at the ground level is presented in Fig. 2. Given the uncertainty introduced by the use of a trajectory model (e.g., a small error in the path of the air parcels can introduce significant error in the predictions), we rely on the average concentrations instead of the predictions of individual hours. Predicted O : C increased during the afternoon due to the production of secondary OA and photochemical processing (evaporation, oxidation in the gas phase, and re-condensation) of the primary OA. The model predictions agree within experimental error with the measurements, with some discrepancies in the afternoon where the model tends to overpredict $\mathrm{O}: \mathrm{C}$. They both suggest relatively oxidized OA with modest average diurnal $\mathrm{O}: \mathrm{C}$ variation. The average predicted $\mathrm{O}: \mathrm{C}$ is 0.64 and the average measured is 0.58 (Table 2). The fractional error and bias for the $4 \mathrm{~h}$ average $\mathrm{O}: \mathrm{C}$ were less than $10 \%$. The results are encouraging especially if one takes into account the typical AMS measurement uncertainties due to a large part to the estimated collection efficiency (for absolute concentrations) and the fragmentation table for the $\mathrm{O}: \mathrm{C}$.

The predicted average $\mathrm{O}: \mathrm{C}$ vertical model profile is compared to the airborne measurements in Fig. 3a. Model predictions agree with the measurements within experimental error and both suggest an oxidized aerosol. The average predicted 


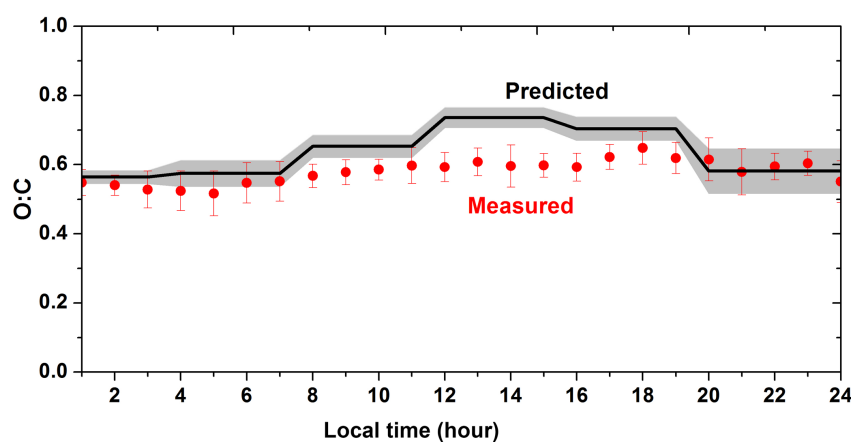

Figure 2. Average O : C diurnal evolution at the ground level in San Pietro Capofiume for the one-bin simulation as an example. The black line shows the $4 \mathrm{~h}$ model average predictions for all simulated days (six plateaus from $4 \mathrm{~h}$ of model predictions) and the shaded area corresponds to 1 standard deviation. The red symbols represent the ground AMS measurements and the error bars correspond to 1 standard deviation.

$\mathrm{O}: \mathrm{C}$ was equal to 0.59 , while the average measured $\mathrm{O}: \mathrm{C}$ was 0.58 . The vertical profile for both the predictions and Zeppelin measurements was relatively flat inside the lowest $1 \mathrm{~km}$.

The predicted average diurnal profile of the OA particle mass concentration for the one-bin case is shown in Fig. 4. The average predicted $\mathrm{OA}$ is equal to $2.6 \mu \mathrm{g} \mathrm{m}^{-3}$ and is predicted to be higher during the nighttime for this specific period. The measurements suggest a relatively flat profile; however, the model predicts higher particle mass concentrations during nighttime due to increased levels of SOA. The average measured particle mass concentration during the same period was $2.8 \mu \mathrm{g} \mathrm{m}^{-3}$. The absolute error was equal to $0.78 \mu \mathrm{g} \mathrm{m}^{-3}$ and the fractional bias was $12 \%$. The anthropogenic SOA and SOA from IVOC (intermediate volatility organic compound) oxidation (SOA-iv) dominate the predicted OA composition, with biogenic SOA increasing during nighttime. SOA-iv is predicted to contribute $36 \%$ to the total OA. Anthropogenic (aSOA-v) and biogenic SOA are predicted to account for 22 and $17 \%$ respectively and SOAsv and POA represent around $10 \%$ each (Fig. S3 in the Supplement). The predicted average diurnal profile of the POA particle mass concentration compared to the HOA concentration from the AMS-PMF results from the ground from Sullivan et al. (2016) is also shown in Fig. S4 in the Supplement. The particle mass concentrations are always less than $0.25 \mu \mathrm{g} \mathrm{m}^{-3}$ and the diurnal profiles seem to agree satisfactorily. The biomass burning contribution is not present during these summer months.

The average vertical predicted profile for all Zeppelin flights is compared with the corresponding measurements in Fig. 3b. The average measured OA for these periods was equal to $4.7 \mu \mathrm{g} \mathrm{m}^{-3}$ while the average predicted $4.2 \mu \mathrm{g} \mathrm{m}^{-3}$. Model predictions are within experimental error for altitudes lower than $700 \mathrm{~m}$. The three data points at higher altitudes
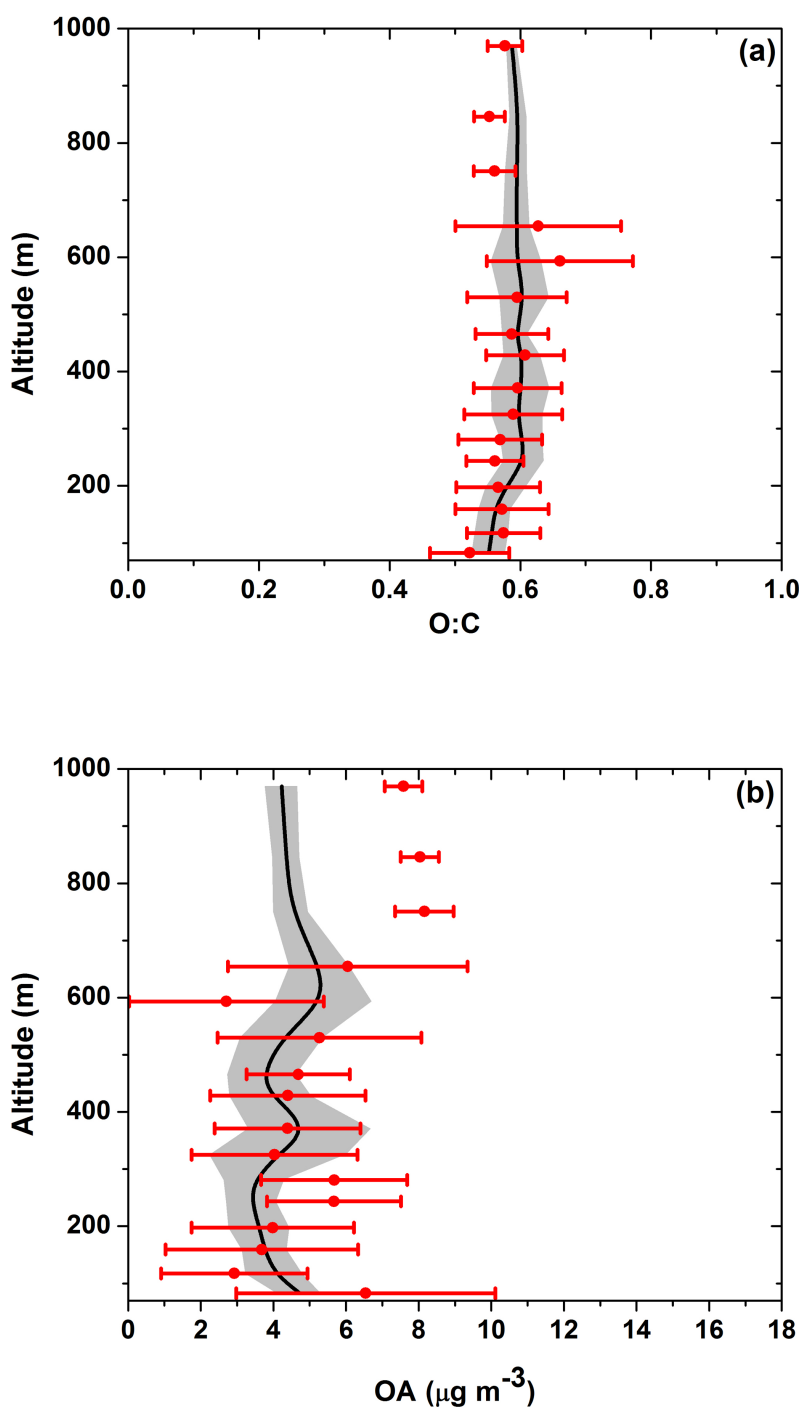

Figure 3. Average vertical predicted and measured (one-bin case, as an example) (a) $\mathrm{O}$ : $\mathrm{C}$ ratio and (b) organic aerosol mass concentration for all the Zeppelin measurements over the Po Valley. The black line shows the model predictions and the shaded areas the standard deviation. The red symbols represent the AMS Zeppelin measurements and the error bars correspond to 1 standard deviation. The discontinuity at the top is due to the results of a single flight on 20 June 2012.

are all from a single flight on 20 June 2012 during which the model underpredicted the OA aloft. Potential problems with the use of data from this flight include the existence of a pollution layer aloft that day that was not captured by the model or some other relatively rare event that took place at that time.

\subsection{Effect of functionalization scheme}

Using the two-bin simple functionalization scheme the fractional error and bias for $\mathrm{O}: \mathrm{C}$ are around $10 \%$, similar to 


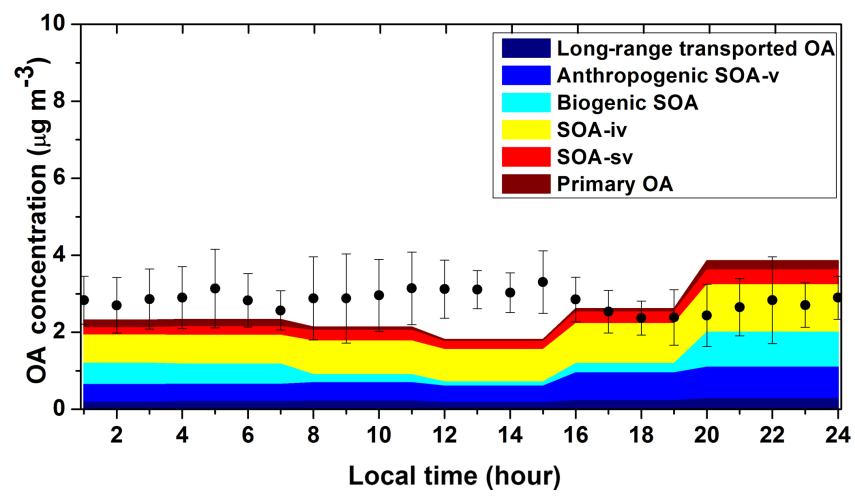

Figure 4. Average diurnal profile of $\mathrm{OA}$ at the ground level in San Pietro Capofiume (one-bin case, as an example). With dark blue we represent the OA from long-range transport, with blue the anthropogenic SOA produced during the oxidation of anthropogenic VOCs (aSOA-v), with cyan the biogenic SOA (bSOA), with yellow the SOA from oxidation of intermediate volatility compounds (SOA-iv), with red the SOA from the oxidation of semivolatile OA (SOA-sv), and finally with dark red the fresh primary organic aerosol (POA). The ground AMS measurements are shown with black symbols and the error bars correspond to 1 standard deviation.

the one-bin parameterization. The average predicted OA is equal to $3.4 \mu \mathrm{g} \mathrm{m}^{-3}$ (Table 3) with similar fractional error and bias with the one-bin case. The average volatility distribution and $\mathrm{O}: \mathrm{C}$ of OA at the ground level is shown in Fig. S2 in the Supplement. The OA mass, using this functionalization scheme, is distributed towards smaller volatilities, compared to the one-bin case, almost one bin to the left (Fig. S2b in the Supplement), while the OA mass is distributed around similar values for the $\mathrm{O}: \mathrm{C}$ with a diurnal ground average equal to 0.63 (Table 2), where 0.58 is the average for the measurements.

The detailed functionalization scheme underpredicted the $\mathrm{O}: \mathrm{C}$, with fractional bias equal to $34 \%$ and an average $\mathrm{O}: \mathrm{C}$ equal to 0.41 (Table 2), when the average measured was 0.58 . This is consistent with the conclusions of Murphy et al. $(2011,2012)$ about the tendency of this aggressive functionalization scheme to seriously underpredict $\mathrm{O}: \mathrm{C}$. Specifically, the high reduction of the volatility of the organic compounds in this parameterization moves them rapidly to the particulate phase where they cannot be oxidized further. Thus, the scheme moves the compounds to the left of the 2D-VBS but with a small slope, so the final predicted $\mathrm{O}: \mathrm{C}$ is low and actually lower than observed. The performance of this scheme was better for the OA mass concentration with an average predicted value equal to $3.2 \mu \mathrm{g} \mathrm{m}^{-3}$ (Table 3), close to the average measured value $\left(2.8 \mu \mathrm{g} \mathrm{m}^{-3}\right)$. The OA particle mass concentration fractional bias was equal to $11 \%$ while the fractional error was $21 \%$. In this functionalization scheme, the predicted OA has a wider distribution in the 2-
D space than the two previous schemes and lower $\mathrm{O}: \mathrm{C}$ and volatilities (Fig. S2c in the Supplement).

\subsection{Effect of bSOA production during aging}

The average predicted $\mathrm{O}: \mathrm{C}$ for the ground level using the one-bin/bSOA parameterization is 0.55 , which is consistent with the measured 0.58 (Table 2). The fractional error and bias of $\mathrm{O}: \mathrm{C}$ are less than $10 \%$. However, the OA concentration is overpredicted with an average value of $3.8 \mu \mathrm{g} \mathrm{m}^{-3}$, compared to the measured $2.8 \mu \mathrm{g} \mathrm{m}^{-3}$ (Table 2). The OA particle mass concentration fractional bias and error were 26 and $30 \%$ respectively. This is consistent with the conclusions of Hermansson et al. (2014), Lane et al. (2008), and Murphy and Pandis (2009) that treating only the functionalization of bSOA while neglecting fragmentation leads to overpredictions of OA concentrations.

The same behavior was observed in the two-bin/bSOA simulation in which PMCAMx-Trj predicted an average ground $\mathrm{O}$ : $\mathrm{C}$ equal to 0.53 with fractional bias less than $10 \%$ but overpredicted $\mathrm{OA}$ with an average equal to $5 \mu \mathrm{g} \mathrm{m}^{-3}$ and a high fractional bias of $54 \%$. Finally, in the DET/bSOA case, the model seriously underpredicted $\mathrm{O}: \mathrm{C}$, with an average value equal to 0.35 and fractional bias equal to $50 \%$, and overpredicted $\mathrm{OA}$ concentration, with an average equal to $5.4 \mu \mathrm{g} \mathrm{m}^{-3}$ and a high fractional bias of $60 \%$. In all of these cases, addition of significant later-generation bSOA production leads to significant errors in the model predictions.

\subsection{The role of fragmentation}

To explore the role of fragmentation the one-bin simple functionalization scheme was first used, assuming additional production of bSOA during aging combined with the fragmentation parameterization varying the fragmentation probability from zero to one. An optimum fragmentation probability equal to 0.15 was estimated (Fig. S5b in the Supplement) by minimizing the absolute error for the predicted OA mass concentrations. All model predictions discussed in the paper were matched in time and space with the measurements. The average predicted $\mathrm{O}: \mathrm{C}$ for this model configuration (one$\mathrm{bin} / \mathrm{bSOA} / b=0.15$ ) was equal to 0.56 , in good agreement with the measurements and a fractional bias of $4 \%$ (Table 2). The average predicted OA was equal to $2.9 \mu \mathrm{g} \mathrm{m}^{-3}$ with a fractional bias of just $2 \%$.

The second functionalization scheme (two-bin case) was also tested without and with bSOA aging (two-bin and two$\mathrm{bin} / \mathrm{bSOA}$ cases respectively). In the first case, the optimum $b$, after minimizing the absolute OA mass concentration error, was estimated to be equal to 0.1 and, in the second case, assuming bSOA aging, it was equal to 0.4 (Figs. S5c and d in the Supplement). For both model configurations, the performance was satisfactory (fractional biases less than $10 \%$ and fractional errors less than $25 \%$ ) for both $\mathrm{O}: \mathrm{C}$ and OA mass (Table 2 and 3). 
In the last test, the detailed functionalization scheme was used. In the previous simulations, the DET and DET/bSOA parameterizations resulted in high underpredictions of the $\mathrm{O}: \mathrm{C}$ and overprediction of the $\mathrm{OA}$ concentration for DET/bSOA case. In the DET parameterization, the optimum $b$ was estimated to be equal to 0.3 and, in the second case, assuming bSOA aging, it was equal to 0.7 (Figs. S5e and $\mathrm{f}$ in the Supplement). These schemes performed well with fractional biases less than $10 \%$ and fractional errors less than $25 \%$ for OA and less than $10 \%$ for O : C.

For all three aging schemes, including suitable fragmentation schemes resulted in satisfactory results compared to the measurements at the ground level. In Fig. S4 in the Supplement all the parameterizations had similar POA concentrations compared to the HOA concentrations from the ground PMF-AMS (positive matrix factorization of the aerosol mass spectrometer) measurements. The situation was similar for the Zeppelin measurements as shown in Fig. S6 in the Supplement. All these parameterizations resulted in similar vertical profiles of $\mathrm{O}: \mathrm{C}$ and $\mathrm{OA}$ with similar agreement with the measurements.

The range of fragmentation probabilities from all cases was high (from 0.1 to 0.7 ) and the model appeared to use it as a correction factor to reduce the SOA produced by the most aggressive schemes. However, both the low and high values of this range are reasonable for lightly and highly substituted organic compounds (Donahue et al., 2012a). There have been a number of studies that have tried to constrain this process for selected systems like squalene particles (Kroll et al., 2009) and a series of alkanes, ketones, aldehydes, and acids (Chacon-Madrid et al., 2010, 2011). While these studies have provided useful insights we are far from constraining this parameter. Additional emphasis on the production of volatile organic compounds (including small organic molecules) during the aging process will clearly help.

\subsection{Synthesis of results}

The previous results suggest that there are seven aging parameterizations from those examined that reproduce well both the ground and Zeppelin measurements. These are

- the simple functionalization scheme and assuming negligible bSOA aging (one-bin case) corresponding to the base case in Murphy et al. (2011);

- the one-bin shift with bSOA aging and a fragmentation probability equal to $15 \%$ (one-bin/bSOA/ $b=0.15$ );

- the two-bin shift without bSOA aging (two-bin);

- the two-bin shift without bSOA aging and a fragmentation probability equal to $10 \%$ (two-bin $/ b=0.1$ );

- the two-bin shift with bSOA aging and a fragmentation probability equal to $40 \%$ (two-bin/bSOA/ $b=0.4$ );

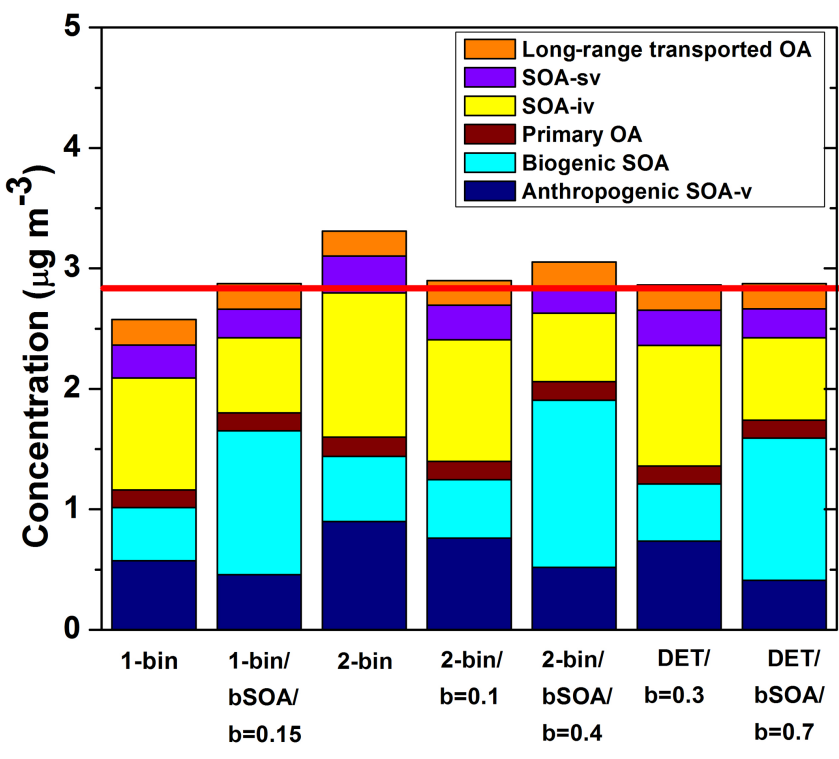

Figure 5. Predicted OA composition for the schemes with good performance for San Pietro Capofiume. The red line indicates the average ground-measured $\mathrm{OA}$ equal to $2.8 \mathrm{\mu g} \mathrm{m}^{-3}$.

- the detailed functionalization scheme, without bSOA aging and a fragmentation probability equal to $30 \%$ $(\mathrm{DET} / b=0.3)$; and

- the detailed functionalization scheme with bSOA aging and fragmentation probability equal to $70 \%$ $(\mathrm{DET} / \mathrm{bSOA} / b=0.7)$.

Parameterizations that appear to be inconsistent with the measurements are the ones that use the detailed functionalization scheme, without any fragmentation schemes, leading to underprediction of the $\mathrm{O}: \mathrm{C}$. Parameterizations including net bSOA production during the chemical aging reactions and neglecting fragmentation were also inconsistent with the measurements resulting in overprediction of the OA levels.

These seven aging schemes predict different OA composition (Fig. 5), while all perform well enough compared to the measurements. Considering the modeling uncertainty introduced by the use of a 1-D trajectory model and the corresponding measurement uncertainties, all models perform satisfactorily. While statistically the performance of the two$\operatorname{bin} / \mathrm{bSOA} / b=0.4$ scheme is a little better than the others, this difference is clearly within experimental and/or modeling error. Anthropogenic SOA from VOCs (aSOA-v) is predicted to contribute between 14 and $27 \%$ of the total OA (Fig. S3a in the Supplement). It is a high contributor for the simulations assuming negligible additional production of bSOA during chemical aging. The parameterization using the faster functionalization scheme (two-bin) predicts the highest percentage of $27 \%$ while the scheme with the detailed functionalization, additional bSOA production, and rapid fragmentation $(\mathrm{DET} / \mathrm{bSOA} / b=0.7)$ predicts the lowest $(14 \%)$. 

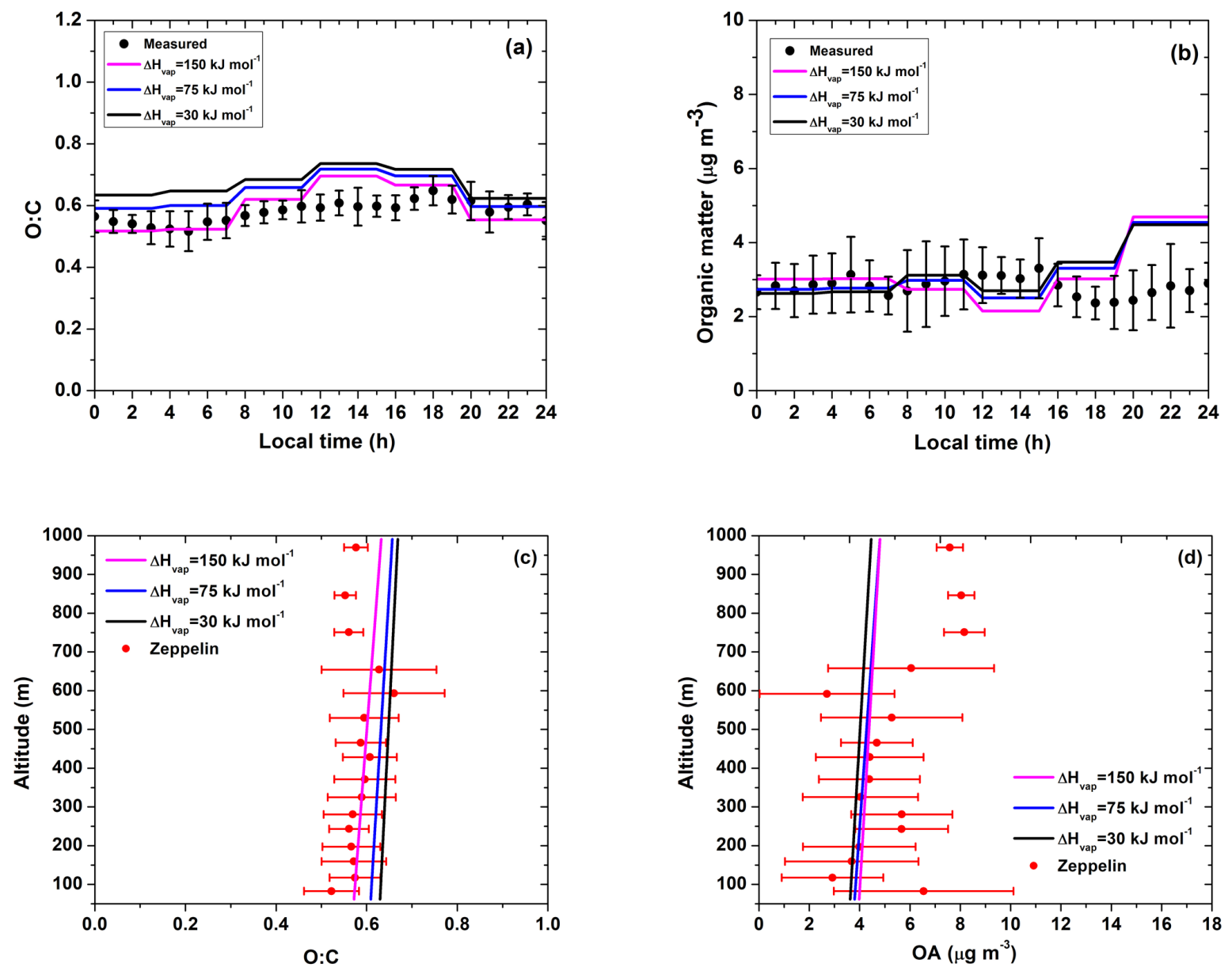

Figure 6. Diurnally averaged (a) $\mathrm{O}: \mathrm{C}$ ratios and (b) organic aerosol mass concentrations. Average vertical organic aerosol (c) $\mathrm{O}$ : $\mathrm{C}$ and (d) organic aerosol mass concentrations assuming in the model $\Delta H_{\mathrm{vap}}=30 \mathrm{~kJ} \mathrm{~mol}^{-1}$ (black line), $\Delta H_{\mathrm{vap}}=75 \mathrm{~kJ} \mathrm{~mol}^{-1}$ (blue line), and $\Delta H_{\text {vap }}=150 \mathrm{~kJ} \mathrm{~mol}^{-1}$ (magenta line) for the Po Valley in Italy. The black symbols show the ground AMS measurements. The red symbols show the Zeppelin measurements. The error bars represent 1 standard deviation.

The predicted contribution of biogenic SOA was the most variable, ranging from 16 to $45 \%$ of the total OA depending on the scheme (Fig. S3b in the Supplement). The highest contribution, as expected, was predicted by the schemes assuming production of bSOA during aging. The highest fraction $(45 \%)$ was predicted using the two-bin shift functionalization parameterization and fragmentation by $40 \%$ (two$\mathrm{bin} / \mathrm{bSOA} / b=0.4)$. The lower bSOA mass concentrations were predicted by the four schemes assuming negligible net bSOA production during aging.

SOA from the oxidation of intermediate volatility compounds (SOA-iv) varied between 19 and $36 \%$ depending on the model (Fig. S3c in the Supplement). The lowest contributions were predicted by the simulations in which the bSOA mass concentration was high. The primary OA (POA) varied from 5 to $6 \%$, the OA from long-range transport from 6 to $8 \%$, and the SOA from evaporation of the primary and subsequent oxidation (SOA-sv) from 7 to $11 \%$.
These results are encouraging because the various parameterizations even if they are quite different give a rather consistent picture (with the exception of the picture of the bSOA maybe) about the various pathways contributing to the OA levels in this area. Additional constraining of these schemes will require applications of the corresponding models in other areas, additional measurements, and probably additional laboratory studies.

\subsection{The role of vaporization enthalpy}

The vaporization enthalpy is a physical property that has always been assumed in chemical transport models with values ranging from very low such as 20 to even $200 \mathrm{~kJ} \mathrm{~mol}^{-1}$ that have been suggested after constraining these values with experimental data (Stanier et al., 2007; Offenberg et al., 2017). In our model, three different effective vaporization enthalpies equal to 30,75 , and $150 \mathrm{~kJ} \mathrm{~mol}^{-1}$ were assumed and used together with the simple functionalization scheme (one-bin 
case). All three simulations predicted the same flat diurnal profile for both the $\mathrm{O}: \mathrm{C}$ and $\mathrm{OA}$ concentration, with differences less than $20 \%$, mostly in the first hours of the day (Fig. 6a, b). The predictions of the scheme with the higher vaporization enthalpy tend to be a little closer to the ground measurements of $\mathrm{O}: \mathrm{C}$. As vaporization enthalpy increased, the predicted $\mathrm{O}: \mathrm{C}$ decreased and $\mathrm{OA}$ concentration increased (Table S1 in the Supplement). However, the differences were small, with the average $\mathrm{O}: \mathrm{C}$ ranging from 0.59 for the $150 \mathrm{~kJ} \mathrm{~mol}^{-1}$ case to 0.64 for the $30 \mathrm{~kJ} \mathrm{~mol}^{-1}$ case, while the measured average value was 0.58 . The fractional biases for $\mathrm{O}: \mathrm{C}$ were similar, ranging from $2 \%$ for a vaporization enthalpy equal to $150 \mathrm{~kJ} \mathrm{~mol}^{-1}$ to $10 \%$ for $30 \mathrm{~kJ} \mathrm{~mol}^{-1}$. The results for the OA concentration were similar.

The comparison of the model predictions with the vertical profiles from the Zeppelin measurements showed similar results (Fig. $6 \mathrm{c}$ and d). The predicted vertical profiles of $\mathrm{O}: \mathrm{C}$ and $\mathrm{OA}$ particle mass concentration were once more not that sensitive to the assumed effective vaporization enthalpy. This lack of sensitivity can be explained by the intricate interplay between the two processes (first-generation production and partitioning as well as chemical aging). Specifically, when a high evaporation enthalpy was used, the first-generation SOA evaporated more at high temperatures and its concentration was reduced. However, now there were more semivolatile vapors available for the aging reactions with the $\mathrm{OH}$. So, these reactions produced more later-generation SOA. The reduction of first-generation SOA (due to evaporation) was offset by the higher SOA from the chemical aging reactions, so the total SOA did not change much. The opposite happened when a lower enthalpy was used. The sensitivity to the vaporization enthalpy was examined for different aging mechanisms and the conclusions were the same.

\section{Conclusions}

The effects of the parameterization of the chemical aging processes of atmospheric organic compounds on organic aerosol (OA) particle mass concentration and chemical composition were investigated by using different formulations of the two-dimensional volatility basis set (2D-VBS) together with ground and airborne measurements in the Po Valley in Italy.

We applied first the simple aging mechanism of the base case (Murphy et al., 2012), presented here as the one-bin case. The advantage of this scheme is that it can be implemented in the 1D-VBS also, so one can get the same performance for OA at a low computational cost. The predictions of the model were satisfactory, both at the ground and aloft, within experimental variability and with fractional biases for the $4 \mathrm{~h}$ average $\mathrm{O}: \mathrm{C}$ and OA concentration around $10 \%$. The average diurnal POA concentration was similar to the HOA concentration from the PMF-AMS ground measure- ments with concentrations less than $0.25 \mu \mathrm{g} \mathrm{m}^{-3}$. The vertical profile for both predictions of the one-bin case and Zeppelin measurements was relatively flat inside the lowest $1 \mathrm{~km}$ and the diurnal variation in $\mathrm{O}: \mathrm{C}$ ratio was modest. They both suggested a relatively oxidized OA for the Po Valley, Italy, with an average $\mathrm{O}: \mathrm{C}$ around 0.6. Anthropogenic SOA and SOA from intermediate volatility compound oxidation dominated the predicted OA composition based on this parameterization.

Seven aging schemes (out of more than a hundred tested), with different assumed functionalization algorithms, bSOA aging, and fragmentation probabilities (ranging from 0.1 to 1) were found to reproduce well the ground and Zeppelin $O$ : $\mathrm{C}$ and OA measurements. Anthropogenic SOA from VOCs was predicted to contribute between 15 and $25 \%$ of the total OA and SOA from the oxidation of intermediate volatility compound oxidation between 20 and $35 \%$. The contribution of biogenic SOA varied from 15 to $45 \%$, depending on the parameterization scheme. POA was around $5 \%$, with similar average diurnal profiles between the different parameterizations and similar to the HOA concentrations from the PMF-AMS ground measurements. The OA from long-range transport varied from 6 to $8 \%$ and the SOA from evaporation of the primary OA and subsequent oxidation from 7 to $11 \%$. These results are encouraging because, despite the uncertainty introduced by the different schemes, their predictions about source contributions are relatively robust. However, the robustness of these schemes, which were tuned to the measurements in a specific area and period, will need to be tested in future work. For the time being, this work can be viewed as a parameter-fitting exercise demonstrating that there are multiple sets of 2D-VBS parameters that can result in predictions consistent with the measurements.

Addition of bSOA produced during the corresponding chemical aging reactions in the functionalization-only schemes resulted in overpredictions of the OA mass concentration. Addition of significant fragmentation (fragmentation probabilities ranging from 15 to $70 \%$ ) was necessary to balance this additional source. This is clearly a topic that deserves additional research both in the laboratory and in the field. The dependence of the fragmentation probability on $\mathrm{O}: \mathrm{C}$ was neglected in this study and should be better addressed in future work.

SOA models rely on the partitioning of the semi-volatile organic vapors between the gas and particulate phases. This process is sensitive to the evaporation enthalpy and changing temperature. However, in our work, there was surprising low sensitivity of predicted OA particle mass concentration and $\mathrm{O}: \mathrm{C}$ both at the ground and aloft to enthalpy of vaporization. Using three different vaporization enthalpies equal to 30,75 , and $150 \mathrm{~kJ} \mathrm{~mol}^{-1}$, the model predictions showed a very similar flat diurnal profile for $\mathrm{O}: \mathrm{C}$ and $\mathrm{OA}$ particle mass concentration at the ground with differences less than $20 \%$ and being within experimental variability. The conclusions for the vertical profiles of the model in comparison to the Zeppelin 
measurements were similar. This behavior is due to the fact that, in the schemes used here, chemical aging cancels to a large extent this sensitivity. The small temperature differences for altitudes up to $600 \mathrm{~m}$ might also partially explain this low sensitivity. There was some weak evidence though that the higher values $\left(150 \mathrm{~kJ} \mathrm{~mol}^{-1}\right)$ are in better agreement with the $\mathrm{O}: \mathrm{C}$ observations at the ground and aloft. This low sensitivity is probably also a feature of analyzing within the boundary layer during only the summer. The interplay between partitioning and chemical aging for example during wintertime would still be present, but the chemical aging should be slower. Future work with three-dimensional models and measurements with high-altitude predictions and/or annual simulations with wintertime predictions may be useful.

Data availability. The data from this work are available upon request from Spyros Pandis (spyros@chemeng.upatras.gr).

\section{The Supplement related to this article is available online at https://doi.org/10.5194/acp-18-10759-2018- supplement.}

Author contributions. EK conducted the simulations, analysed the results, and wrote the paper. BNM assisted in the development and application of PMCAMx-Trj. LP, HH, AW, and FR were responsible for the ground measurements used in this study. AKS and TFM were responsible for the Zeppelin measurements used in this study. SNP was responsible for the main design of the study and the synthesis of the results. All authors were involved in discussing the results and improved the paper by commenting and proofreading.

Competing interests. The authors declare that they have no conflict of interest.

Acknowledgements. This research was supported by the PEGASOS project funded by the European Commission under the Framework Program 7 (FP7-ENV-2010-265148) and grant 1455244 from the US National Science Foundation.

Edited by: Thomas Röckmann

Reviewed by: two anonymous referees

\section{References}

Caiazzo, F., Ashok, A., Waitz, I. A., Yim, S. H. L., and Barrett, S. R. H.: Air pollution and early deaths in the United States. Part I: Quantifying the impact of major sectors in 2005, Atmos. Environ., 79, 198-208, 2013.

Cappa, C. D. and Wilson, K. R.: Multi-generation gas-phase oxidation, equilibrium partitioning, and the formation and evolution of secondary organic aerosol, Atmos. Chem. Phys., 12, 9505-9528, https://doi.org/10.5194/acp-12-9505-2012, 2012.

Chacon-Madrid, H. J. and Donahue, N. M.: Fragmentation vs. functionalization: chemical aging and organic aerosol formation, Atmos. Chem. Phys., 11, 10553-10563, https://doi.org/10.5194/acp-11-10553-2011, 2011.

Chacon-Madrid, H. J., Presto, A. A., and Donahue, N. M.: Functionalization vs. fragmentation: n-aldehyde oxidation mechanisms and secondary organic aerosol formation, Phys. Chem. Chem. Phys., 12, 13975-13982, 2010.

Donahue, N. M., Robinson, A. L., Stanier, C. O., and Pandis, S. N.: Coupled partitioning, dilution, and chemical aging of semivolatile organics, Environ. Sci. Technol., 40, 2635-2643, 2006.

Donahue, N. M., Kroll, J. H., Pandis, S. N., and Robinson, A. L.: A two-dimensional volatility basis set: 1. organic-aerosol mixing thermodynamics, Atmos. Chem. Phys., 11, 3303-3318, https://doi.org/10.5194/acp-11-3303-2011, 2011.

Donahue, N. M., Epstein, S. A., Pandis, S. N., and Robinson, A. L.: A two-dimensional volatility basis set - Part 2: Diagnostics of organic-aerosol evolution, Atmos. Chem. Phys., 12, 615-634, https://doi.org/10.5194/acp-12-615-2012, 2012a.

Donahue, N. M., Henry, K. M., Mentel, T. F., Kiendler-Scharr, A., Spindler, C., Bohn, B., Brauers, T., Dorn, H. P., Fuchs, H., Tillmann, R., Wahner, A., Saathoff, H., Naumann, K. H., Möhler, O., Leisner, T., Müller, L., Reinnig, M. C., Hoffmann, T., Salo, K., Hallquist, M., Frosch, M., Bilde, M., Tritscher, T., Barmet, P., and Baltensperger, U.: Aging of biogenic secondary organic aerosol via gas-phase $\mathrm{OH}$ radical reactions, P. Natl. Acad. Sci., 109, 13503-13508, 2012b.

Draxler, R., Stunder, B., Rolph, G., Stein, A., and Taylor, A.: HYSPLIT4 User's Guide, NOAA Silver Spring, MD, 2009.

Fountoukis, C., Racherla, P. N., Denier van der Gon, H. A. C., Polymeneas, P., Charalampidis, P. E., Pilinis, C., Wiedensohler, A., Dall'Osto, M., O'Dowd, C., and Pandis, S. N.: Evaluation of a three-dimensional chemical transport model (PMCAMx) in the European domain during the EUCAARI May 2008 campaign, Atmos. Chem. Phys., 11, 10331-10347, https://doi.org/10.5194/acp-11-10331-2011, 2011.

Gilardoni, S., Vignati, E., Cavalli, F., Putaud, J. P., Larsen, B. R., Karl, M., Stenstrom, K., Genberg, J., Henne, S., and Dentener, F.: Better constraints on sources of carbonaceous aerosols using a combined ${ }^{14} \mathrm{C}$ - macro tracer analysis in a European rural background site, Atmos. Chem. Phys., 11, 5685-5700, https://doi.org/10.5194/acp-11-5685-2011, 2011.

Guenther, A., Karl, T., Harley, P., Wiedinmyer, C., Palmer, P. I., and Geron, C.: Estimates of global terrestrial isoprene emissions using MEGAN (Model of Emissions of Gases and Aerosols from Nature), Atmos. Chem. Phys., 6, 3181-3210, https://doi.org/10.5194/acp-6-3181-2006, 2006.

Hermansson, E., Roldin, P., Rusanen, A., Mogensen, D., Kivekäs, N., Väänänen, R., Boy, M., and Swietlicki, E.: Biogenic SOA formation through gas-phase oxidation and gas-to-particle partitioning - a comparison between process models of varying complexity, Atmos. Chem. Phys., 14, 11853-11869, https://doi.org/10.5194/acp-14-11853-2014, 2014.

Hildebrandt Ruiz, L., Paciga, A. L., Cerully, K. M., Nenes, A., Donahue, N. M., and Pandis, S. N.: Formation and aging of secondary organic aerosol from toluene: changes in chemical composition, 
volatility, and hygroscopicity, Atmos. Chem. Phys., 15, 83018313, https://doi.org/10.5194/acp-15-8301-2015, 2015.

IPCC (Intergovernmental Panel on Climate Change): Climate Change 2013: The Physical Science Basis. Contribution of Working Group I to the Fifth Assessment Report of the Intergovernmental Panel on Climate Change, edited by: Stocker, T. F., Qin, D., Plattner, G.-K., Tignor, M., Allen, S. K., Boschung, J., Nauels, A., Xia, Y., Bex, V., and Midgley, P. M., Cambridge University Press, Cambridge, UK and New York, NY, USA, 2013.

Kroll, J. H., Smith, J. D., Che, D. L., Kessler, S. H., Worsnop, D. R., and Wilson, K. R.: Measurement of fragmentation and functionalization pathways in the heterogeneous oxidation of oxidized organic aerosol, Phys. Chem. Chem. Phys., 11, 8005-8014, 2009.

Kulmala, M., Asmil, A., Lappalainen, H. K., Carslaw, K. S., Pöschl, U., Baltensperger, U., Hoy, O., Brenquier, J.-L., Pandis, S. N., Facchini, M. C., Hansson, H. C., Wiedensohler, A., and O'Dowd, C. D.: Introduction: European Integrated Project on Aerosol Cloud Climate and Air Quality interactions (EUCAARI) - integrating aerosol research from nano to global scales, Atmos. Chem. Phys., 9, 2825-2841, https://doi.org/10.5194/acp-9-28252009, 2009.

Lane, T. E., Donahue, N. M., and Pandis, S. N.: Simulating secondary organic aerosol formation using the volatility basis-set approach in a chemical transport model, Atmos. Environ., 42, 7439-7451, 2008.

Murphy, B. N. and Pandis, S. N.: Simulating the formation of semivolatile primary and secondary organic aerosol in a regional chemical transport model, Environ. Sci. Technol., 43, 47224728, 2009.

Murphy, B. N. and Pandis, S. N.: Exploring summertime organic aerosol formation in the eastern United States using a regionalscale budget approach and ambient measurements, J. Geophys. Res., 115, D24216, https://doi.org/10.1029/2010jd014418, 2010.

Murphy, B. N., Donahue, N. M., Fountoukis, C., and Pandis, S. N.: Simulating the oxygen content of ambient organic aerosol with the 2D volatility basis set, Atmos. Chem. Phys., 11, 7859-7873, https://doi.org/10.5194/acp-11-7859-2011, 2011.

Murphy, B. N., Donahue, N. M., Fountoukis, C., Dall'Osto, M., Dowd, C. O., Kiendler-Scharr, A., and Pandis, S. N.: Functionalization and fragmentation during ambient organic aerosol aging: application of the 2-D volatility basis set to field studies, Atmos. Chem. Phys., 12, 10797-10816, https://doi.org/10.5194/acp-1210797-2012, 2012.

Murphy, B. N., Donahue, N. M., Robinson, A. L., and Pandis, S. N.: A naming convention for atmospheric organic aerosol, Atmos. Chem. Phys., 14, 5825-5839, https://doi.org/10.5194/acp14-5825-2014, 2014.

Ng, N. L., Kroll, J. H., Keywood, M. D., Bahreini, R., Varutbangkul, V., Flagan, R. C., and Seinfeld, J. H.: Contribution of first- versus second-generation products to secondary organic aerosols formed in the oxidation of biogenic hydrocarbons, Environ. Sci. Technol., 40, 2283-2297, 2006.

O’Dowd, C. D., Langmann, B., Varghese, S., Scannell, C., Ceburnis, D., and Facchini, M. C.: A combined organic-inorganic sea spray source function, Geophys. Res. Lett., 35, L01801, https://doi.org/10.1029/2007GL030331, 2008.

Offenberg, J. H., Lewandowski, M., Kleindienst, T. E., Docherty, K. S., Jaoui, M., Krug, J., Riedel, T. P., and Olson D. A.: Predicting
Thermal Behavior of Secondary Organic Aerosols, Environ. Sci. Technol., 51, 9911-9919, 2017.

Pandis, S. N., Harley R. A., Cass G. R., and Seinfeld J. H.: Secondary organic aerosol formation and transport, Atmos. Environ., 26, 2266-2282, 1992.

Pope III, C. A., Ezzati, M. and Dockery, D. W.: Fine-particulate air pollution and life expectancy in the United States, New England J. Med., 360, 376-386, 2009.

Sheehan, P. E. and Bowman, F. M.: Estimated effects of temperature on secondary organic aerosol concentrations, Environ. Sci. Technol., 35, 2129-2135, 2001.

Sofiev, M., Lanne, M., Vankevich, R., Prank, M., Karppinen, A., and Kukkonen, J.: Impact of wild-land fires on European air quality in 2006-2008, Modeling, Monitoring and Management of Forest Fires, WIT Trans. Ecol. Envir., 119, 353-361, 2008a.

Sofiev, M., Vankevich, R., Lanne, M., Koskinen, J., and Kukkonen, J.: On integration of a Fire Assimilation System and a chemical transport model for near-real-time monitoring of the impact of wild-land fires on atmospheric composition and air quality, Modeling, Monitoring and Management of Forest Fires, WIT Trans. Ecol. Environ., 119, 343-351, 2008b.

Stanier, C. O., Pathak, R. K., and Pandis, S. N.: Measurements of the volatility of aerosols from $\alpha$-pinene ozonolysis, Environ. Sci. Technol., 41, 2756-2763, 2007.

Sullivan, A. P., Hodas, N., Turpin, B. J., Skog, K., Keutsch, F. N., Gilardoni, S., Paglione, M., Rinaldi, M., Decesari, S., Facchini, M. C., Poulain, L., Herrmann, H., Wiedensohler, A., Nemitz, E., Twigg, M. M., and Collett Jr., J. L.: Evidence for ambient dark aqueous SOA formation in the Po Valley, Italy, Atmos. Chem. Phys., 16, 8095-8108, https://doi.org/10.5194/acp16-8095-2016, 2016.

Szidat, S., Jenk, T. M., Synal, H.-A., Kalberer, M., Wacker, L., Hajdas, I., Kasper-Giebl, A., and Baltensperger, U.: Contributions of fossil fuel, biomass-burning, and biogenic emissions to carbonaceous aerosols in Zurich as traced by 14C, J. Geophys. Res., 111, D07206, https://doi.org/10.1029/2005JD006590, 2006.

Tritscher, T., Dommen, J., DeCarlo, P. F., Barmet, P. B., Pra-plan, A. P., Weingartner, E., Gysel, M., Prévôt, A. S. H., Riipinen, I., Donahue, N. M., and Baltensperger, U.: Volatility and hygroscopicity of aging secondary organic aerosol in a smog chamber, Atmos. Chem. Phys., 11, 11477-11496, https://doi.org/10.5194/acp-1111477-2011, 2011.

Visschedijk, A. J., Zandveld, P., and Denier van der Gon, H. A. C.: TNO Report 2007 A-R0233/B: A high resolution gridded European emission database for the EU integrated project GEMS, Organization for Applied Scientific Research, the Netherlands, 2007.

Yttri, K. E., Simpson, D., Nøjgaard, J. K., Kristensen, K., Genberg, J., Stenström, K., Swietlicki, E., Hillamo, R., Aurela, M., Bauer, H., Offenberg, J. H., Jaoui, M., Dye, C., Eckhardt, S., Burkhart, J. F., Stohl, A., and Glasius, M.: Source apportionment of the summer time carbonaceous aerosol at Nordic rural background sites, Atmos. Chem. Phys., 11, 13339-13357, https://doi.org/10.5194/acp-11-13339-2011, 2011.

Zhang, Q., Jimenez, J. L., Canagaratna, M. R., Allan, J. D., Coe, H., Ulbrich, I., Alfarra, M. R., Takami, A., Middlebrook, A. M., Sun, Y. L., Dzepina, K., Dunlea, E., Docherty, K., DeCarlo, P. F., Salcedo, D., Onasch, T., Jayne, J. T., Miyoshi, T., Shimono, A., Hatakeyama, S., Takegawa, N., Kondo, Y., 
Schneider, J., Drewnick, F., Borrmann, S., Weimer, S., Demerjian, K., Williams, P., Bower, K., Bahreini, R., Cottrell, L., Griffin, R. J., Rautiainen, J., Sun, J. Y., Zhang, Y. M., and Worsnop, D. R.: Ubiquity and dominance of oxygenated species in organic aerosols in anthropogenically-influenced Northern Hemisphere midlatitudes, Geophys. Res. Lett., 34, L13801, https://doi.org/10.1029/2007GL029979, 2007.
Zhao, B., Wang, S., Donahue, N. M., Chuang, W., HildebrandtRuiz, L., Ng, N. L., Wang, Y., and Hao, J.: Evaluation of onedimensional and two-dimensional volatility basis sets in simulating the aging of secondary organic aerosol with smog-chamber experiments, Environ. Sci. Technol., 49, 2245-2254, 2015. 